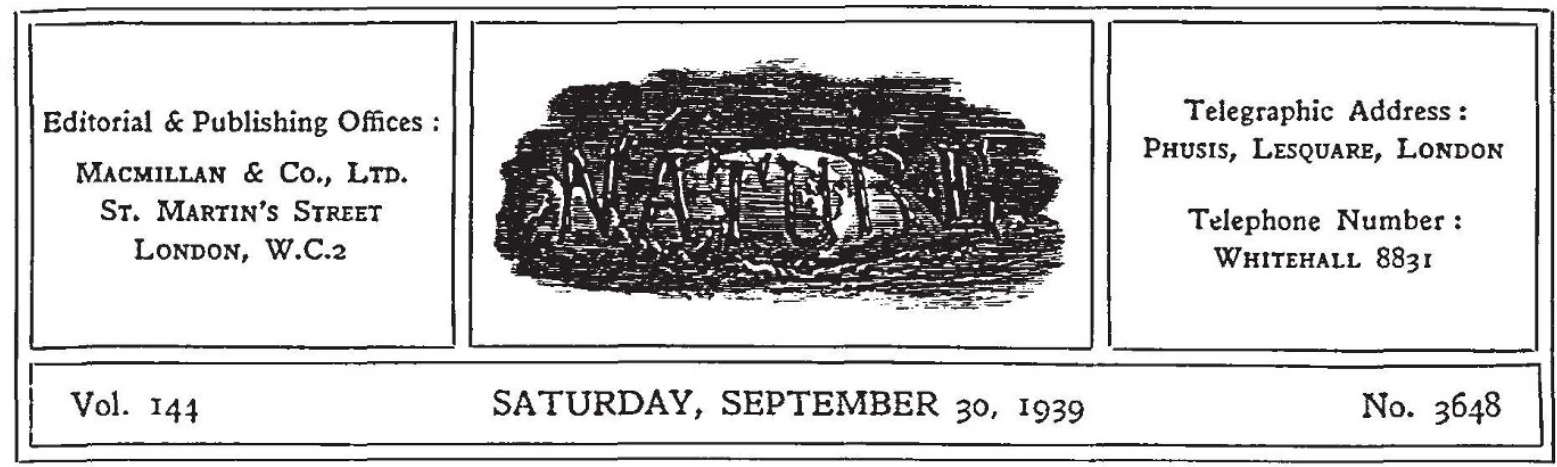

\title{
SCIENCE AND SOCIAL PIONEERING
}

$\mathrm{T}$ HE first British and American Association Lecture was to have been delivered at Dundee on September 5 by Dr. Isaiah Bowman, who had chosen the title "Scienco and Social Pioncering" for his lecture. Circumstances prevented its delivery, but it is available in printed form, and it provides a thoughtful analysis of views on the contribution of science to social welfare and to that process of continuously planned advance across the threshold of experience which may well be called social pioneering.

The opinions as to the extent to which science has added to man's cultural possibilities, given him a better way of thinking through his difficulties, or raised his hopes for a more ethical civilization, which Dr. Bowman has collected from American sources outside the ranks of science, are largely to be met in Great Britain and in France also, both within and without the ranks of scientific workers. Science, it is at last being realized, is a part of human life, not something separate and distinct. As human experience, it is not universal, a summation of knowledge applicable and useful to the whole of life; it is rather a thing of limited categories, a special form of human interests.

To most men of science, science is only a specialized form of experience, but the study of the background of social life against which science has developed raises problems foreign to this outlook. Any serious attempt to probe back to the social origins and social consequences of scientific discovery demands that scientific workers shall at least make an effort to guard against the dangers of their own specialization. To be fully scientific, they must be aware not only of their own point of advance but also of the advancing front of science.
We should not indeed despise specialization, and Dr. Bowman points out that specialization has increased the satisfaction of many of our fundamental material needs. If the spiritual gains at the moment seem in deplorable contrast to the material benefits, it should be remembered that one of the greatest achievements of science is its emphasis upon free inquiry-the mind itself in command, driven by curiosity and the sense of adventure. Civilization itself can well be considered an adventure in change, and science has become one of the greatest adventures of our time, partly because it deals with the edge of the possibilities. Man is changing his own possibilities as well as those of his world as he goes along. He is at the centre of his own creative experiment. What science supplies is not at all an addition, positive and beneficial, until men have proved it so, and with the addition of things and forces, social and natural, good and bad, ever new possibilities are emerging.

This insistence on the spirit of adventure is indeed one of the keynotes of Dr. Bowman's address. The new frontiers opened up by science in old communities make demands on the spirit of man not less than those made in the pioneering days in a new continent. The play of forces involved in the far-reaching movements and cultural changes of a scientific age, whether solfinitiated and free or guided by government, represents a development of high interest in the social field. Vital leadership, courage and local pride as well as equipment and the experimental point of view are required.

Moreover, we have to remember that what we gather of scientific knowledge concerning society and how it might be improved form one set of 
data; to persuade or to exercise control to bring about desired ends is quite another. Society is built upon beliefs, traditions, prejudices, suppositions and philosophies as well as facts, institutions, inventions and material-all supported by power or force exercised through time. Every advance in applied science calls for a tighter and more inclusive social organization, and while in democratic countries the adoption or rejection of ideas may be freely debated or contested, it is premature to suppose that even democracy ensures continued freedom.

What Dr. Bowman terms social pioneering is concerned with culture in the making, with environment that becomes understood through thinking about the conditions of trial and the effects of error. It deals with new social forms or old forms adapted to new situations, and becomes ever more complex and overpowering for the individual. Such conditions naturally make planning more uncertain, because of unpredictable turns and their effects, unforeseen impacts or disturbances; and the risks in social planning are accentuated if attempts are made to accelerate it, as in an emergency, without due regard for the time-factor.

None the less, the first duty of an intelligent society in this age is to scek out the causes of things. The scientific method is nowhere needed so much as in the sorting-out of causes and the recognition of the action of the forces supposed to be at the root of our troubles ; the first step, however, must be the scientific study of the field of science itself and the conscious planning of policy and research with regard to the social needs of the period and the social functions of science. We cannot be sure that more scientific knowledge will resolve the conflicts between classes, reduce the arrogance of nationalism and diminish the chances of war, but we can at least hope that it will assist in providing a more even-tempered attitude and greater readiness to accept findings even when they involve the disturbance of sectional interests.

Social forms, as Dr. Bowman reminds us, cannot keep pace with creative thought. A time lag is inevitable, because we have found no way to teach and test ideas except through timeconsuming and often inconclusive experience, and no one branch of study can solve the whole array of problems of a people. Huch more could be done, however, by combined effort on the lines of the team-work which in industrial problems, for example, has yielded brilliant results through the efforts of workers in different branches of physical science concentrated on a single objective. The realization by an increasing number of scientific workers to-day that social action is imperative if freedom of thought and investigation are to be preserved for science itself already provides a stimulus. This consciousness is gradually overcoming the reluctance of those who fear the introduction from politics of bias or prejudice, for the pace at which events move demonstrates that even inaction has political consequences.

The formation of the new Division for the Social and International Relations of Science is one of the most significant recent expressions of this urge to advance science beyond the mere study of Nature at the level of inanimate Nature to the level of men in their group activity. Dr. Bow. man's address attempts no positive and final answers as to the solutions of many of the problems thus opened up before us, but his presenta. tion of man's endless adventure in progress reminds us that science is our greatest inspirer of hope. Even in these sombre days of anxiety, it holds out the rational hope that the triumphant methods that have given us deeper understanding and increased efficiency as biological and social mechanisms, will one day give us a still deeper insight into the nature of man and what he may become under rational control.

What gives special pertinence to Dr. Bowman's insistence on this element of pioneering and invention is the change in the nature or emphasis of scientific method. Just when concern with the impact of science on society and with the efiect of society on science itself is growing within the ranks of science, scientific workers are coming to realize that there are limits to the extent to which the scientific method of isolation in experiment can be even approximately used. The widening front of science synchronizes, as Prof. H. Levy has pointed out, with the necessity for a drastic change in scientific method itself. It is not merely in social science that the experimenter must become an integral part of the process itself.

The wider view of scientific method, which recognizes the limits within which even a statistical validity can be given to simple repetition, and admits that every scientific experiment is a piece of scientific history and therefore a piece of social history, compels us also to recognize the inter-relation of all phenomena and to sce the role taken by each element in relation to every other. In scientific work, failure to appreciate 
fully dialectical change may have comparatively slight consequences; the social repercussions of failure to appreciate the dialectical changes produced by and on science in its interaction with society may be almost catastrophic.

Because we do not in general take a scientific view of the processes of change that are manifested in socicty, and because men of science themselves fail to see that the scientific method requires qualitative transformation before it can be applied to the active handling of those issues, we tend to become mere passive onlookers in a course of events which it should be the first scientific duty of all men to control as they ultimately would control any laboratory process.
The address prepared by Dr. Bowman appeals to the characteristic scientific spirit, which cannot rest with unexplored fields before it. The realm of social action itself is the new laboratory, and the steps towards the control of social processes-the taking of political action and the making of social history-are, first an understanding of the interplay of cause and effect in the sense of the new statistical and dialectical method, and then a decision on the new processes which are to be brought into play to transform the situation qualitatively. In this new and wider field, science will yet forge new and appropriate techniques and wield them as effectively as in the physical domain itself.

\section{FISH MOVEMENTS AND FISHPASSES}

La mécanique du poisson de rivière Qualités nautiques du poisson; ses méthodes locomotrices, ses eapacités; ses limites; résistances du fluide; effet de la vitesse, de la pente; résistance de seuil. Par G. Denil. Pp. 395. (Bruxelles : Goemaere, Imprimeure du Roi, 1938.) n.p.

GOME thirty-two years ago, G. Denil, at that $S$ time chief engineer of Belgian Public Works, stood by a new weir, $3.5 \mathrm{~m}$. in height, and lacking a fishpass of any kind whatever. As he watched the tail water of the dam, he was struck by the frantic and necessarily unsuccessful efforts of many salmon to surpass this obstacle by leaps, and also their wholesale destruction following exhaustion, by their overcrowding in a restricted channel, and at the hands of fishermen who had no difficulty in capturing their helpless prey.

On thinking over the complex problems which were involved, Denil resolved to seek a full understanding of the conditions necessary for the pro tection of migratory fishes, and to construct fishpasses so economically that they might become integral parts of all weirs which interrupt the upstream passage of the migrants. So early as 1909 he was able to describe in a long and exhaustive paper his first new successful fishpass, based on the principle that the obstacles involved are oblique to the main waterflow and are spaced so closely that, instead of creating alternate pools and waterjets, they derive secondary streams from the main flow, so that the abrupt re-entrance of these streams causes an energy dissipation of considerable intensity.
Subsequent to the publication mentioned above Denil constructed and controlled a number of fishpasses of exactly the same type and proceeded to improve his system, keeping always in mind the combination of theoretical considerations and of laboratory experiments with observations of the suceessful control of the passes already in operation. Until 1936 he published very little on the subject of his work. In that year he began a long series of articles published in the Annales des Travaux Publiques de Belgique. These articles are brought together in the present book, the title of which, though long, still gives an inadequate indication of the contencs.

The first chapter relates to structural features of salmon-like and elongated white fish. The second contains an analysis, depending to a large extent on the basic work of Breder, of their various types of locomotion; swimming against the stream; jumping; and driving with the stream being particularly considered. In the third chapter, the eel and its locomotion are discussed, comparisons being made with matters already' considered and also with the sea lampreys. In the fourth chapter, the author describes his own experiments on the velocity-resistance of fish-like bodies. In his fifth chapter, he reports on his own measurements and on those of Kreitman and others regarding the greatest relative velocity of fish swimming against a stream, that is, on the 'limit of swimming velocity'. He adds, however, that to attribute direct and decisive importance to this limit, is to accept by implication the hypothesis -never previously stated explicitly, but certainly not questioned either-that the swimming ability 